\title{
Determining the Environmental Potentials of Urban Pavements by Applying the Cradle-to-Cradle LCA Approach for a Road Network of a Midscale German City
}

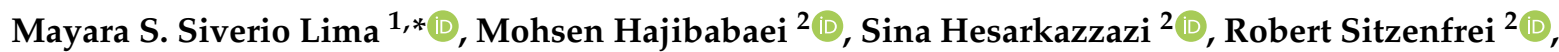 \\ Alexander Buttgereit ${ }^{3}$, Cesar Queiroz ${ }^{4}\left(\mathbb{1}\right.$, Viktors Haritonovs ${ }^{5}$ and Florian Gschösser ${ }^{1}(\mathbb{C}$ \\ 1 Department of Structural Engineering and Material Sciences, University of Innsbruck, 6020 Innsbruck, Austria; \\ florian.gschoesser@uibk.ac.at \\ 2 Department of Infrastructure Engineering, University of Innsbruck, 6020 Innsbruck, Austria; \\ mohsen.hajibabaei@uibk.ac.at (M.H.); sina.hesarkazzazi@uibk.ac.at (S.H.); robert.sitzenfrei@uibk.ac.at (R.S.) \\ 3 Department of Mobility and Civil Engineering of Münster, 48155 Münster, Germany; abuttgereit@gmx.net \\ 4 The World Bank, Washington, DC 20433, USA; queiroz.cesar@gmail.com \\ 5 Department of Roads and Bridges, Riga Technical University, LV-1658 Riga, Latvia; viktors.haritonovs@rtu.lv \\ * Correspondence: mayara.siverio-lima@uibk.ac.at; Tel.: +43-512-507-63109
}

Citation: Siverio Lima, M.S.; Hajibabaei, M.; Hesarkazzazi, S.; Sitzenfrei, R.; Buttgereit, A.; Queiroz, C.; Haritonovs, V.; Gschösser, F. Determining the Environmental Potentials of Urban Pavements by Applying the Cradle-to-Cradle LCA Approach for a Road Network of a Midscale German City. Sustainability 2021, 13, 12487. https://doi.org/ $10.3390 /$ su132212487

Academic Editors: Mayca

Rubio-Gámez and Fernando Moreno-Navarro

Received: 12 October 2021

Accepted: 8 November 2021

Published: 12 November 2021

Publisher's Note: MDPI stays neutral with regard to jurisdictional claims in published maps and institutional affiliations.

Copyright: (c) 2021 by the authors. Licensee MDPI, Basel, Switzerland. This article is an open access article distributed under the terms and conditions of the Creative Commons Attribution (CC BY) license (https:// creativecommons.org/licenses/by/ $4.0 /)$.

\begin{abstract}
This study used a cradle-to-cradle Life Cycle Assessment (LCA) approach to evaluate the environmental potentials of urban pavements. For this purpose, the urban road network of the City of Münster (Germany) was selected as the case study, and comprehensive data for several phases were collected. The entire road network is composed of flexible pavements designed according to specific traffic loads and consists of main roads (MRs), main access roads (MARs), and residential roads (RSDTs). Asphalt materials, pavement structures, and maintenance strategies are predefined for each type of road and are referred to as "traditional" herein. Some pavement structures have two possible maintenance strategies, denoted by " $\mathrm{A}$ " and " $\mathrm{B}$ ", with distinguished periods of intervention. To evaluate the impact of using recycled materials, we considered alternative pavement structures composed of asphalt materials containing a greater amount of reclaimed asphalt pavement (RAP). The study was carried out considering analysis periods of 20,50, 80, and 100 years and using two indicators: non-renewable cumulative energy demand (nr-CED) and global warming potential (GWP). The results show that the use of higher amounts of RAP can mitigate negative environmental impacts and that certain structures and maintenance strategies potentially enhance the environmental performance of road pavements. This article suggests initiatives that will facilitate the decisionmaking process of city administrators to achieve more sustainable road pavement constructions and provides an essential dataset inventory to support future environmental assessment studies, particularly for European cities.
\end{abstract}

Keywords: urban pavements; asphalt mixtures; environmental impacts; sustainability

\section{Introduction}

The climate change and the current environmental crises have intensified the global pursuit for sustainability, pressuring governments and city administrators to promote more sustainable practices [1], and to seek solutions for the most relevant areas of concern such as the transportation sector, which is responsible for approximately $25 \%$ of Europe's greenhouse gas emissions and $15 \%$ of the global share [2,3].

The environmental impacts caused by the transportation sector come from distinct sources: road construction, maintenance and rehabilitation procedures, vehicles and userrelated emissions, end-of-life of the structure [4], etc.

Particularities such as the pavement conditions and the deterioration over time directly influences the rolling resistance of the pavement, affecting the safety, noise level, $\mathrm{CO}_{2}$ emissions, and fuel consumption of vehicles [5-9]. Therefore, decisions such as defining the 
least impactful material to construct urban roads, the pavement design, and the periodicity of interventions have a higher impact on the overall impacts caused by roads [10].

A big share of the impact generated by the construction of roads is from the production of pavement materials and additional industrial processes, which make up $21 \%$ of the greenhouse gas emissions $[6,11]$. Many researchers agree that using recycled materials, byproducts, and waste materials to build pavement structures helps mitigate environmental impacts and reduces the overall cost $[6,8,12-16]$.

To support the decision-making process, Life Cycle Assessment (LCA) tools are often applied to help stakeholders to select environmentally appropriate materials, pavement designs, and rehabilitation practices within an optimized budget, without compromising the quality of the road pavement [17].

Studies have shown that LCA tools $[15,16,18-21]$ can provide a long-term perspective by comparing different solutions and possibilities for urban pavements [10]. However, finding the best materials and structures and an "optimal" maintenance and rehabilitation strategy that can ensure acceptable road conditions, lower agency-user costs, and reduced environmental-social impacts [22] requires complex data analysis and is strongly influenced by local conditions.

In collaboration with a European Union project titled "SAFERUP! (Sustainable, Accessible, Safe, Resilient, and Smart Urban Pavements)", the Department of Mobility and Civil Engineering of the City of Münster aims to improve the sustainability of its urban roads by using LCA to evaluate existing asphalt materials, pavement structures, and maintenance strategies.

In order to assist Münster and other cities to embrace the Agenda 2030 and enhance the environmental performance of the urban road network, this study assesses the environmental impacts of Münster's road network-which is entirely composed of flexible pavements-using the cradle-to-cradle approach with closed-loop recycling. Therefore, all life cycle phases, such as raw material extraction, asphalt material production, transportation, pavement construction, maintenance procedures, deconstruction, and recycling processes were considered in the analysis.

In addition to the traditional pavement structures currently adopted in Münster, we simulated alternative options by selecting asphalt materials with the highest RAP content available at the asphalt plant to fabricate the distinct layers of the pavement. Different maintenance strategies were applied to either the traditional and alternative pavement structures and analysis periods of 20,50, 80 and 100 years were considered.

Finally, this study aims to compare materials, pavement structures, and maintenance strategies that can be used to preserve the urban road network of cities and provide an extensive dataset to support future LCA studies.

\section{Urban Pavements in Münster, Germany}

In Münster, the pavements are designed according to the traffic load (Bk, "Belastungsklasse" in German) in terms of 10-ton axle passages (e.g., 10 to 32 million for Bk 32) and are categorized as main roads (MRs), main access roads (MARs), and residential roads (RSDTs).

The road department of Münster follows the German Guideline [23] "RStO 12: Guidelines for the standardization of pavement structures of traffic areas" that predefines certain pavement structures to be used, which are referred to as "traditional structures" herein and are abbreviated as " $\mathrm{T}$ ".

The MRs and MARs are composed of four layers, while the RSDTs have only three. The asphalt materials used in the surface, binder, and base layers can either be stone mastic asphalt (SMA) or asphalt concrete (AC) and may partially be composed of RAP.

To assess the environmental benefits and limitations of using RAP, "modified structures", abbreviated as "M" herein, were constructed using asphalt mixtures with the highest content of RAP available. 
The specifications, such as load class, materials, and thickness, of the analyzed pavements are listed in Table 1.

Table 1. Pavement structure analysis.

\begin{tabular}{|c|c|c|c|c|c|c|}
\hline \multirow[b]{2}{*}{ Type } & \multicolumn{3}{|c|}{ TRADITIONAL STRUCTURES } & \multicolumn{3}{|c|}{ MODIFIED STRUCTURES } \\
\hline & Load Class & Material & Thickness (cm) & Load Class & Material & Thickness (cm) \\
\hline \multirow{4}{*}{ Main Roads } & \multirow{4}{*}{ Bk 32-T } & SMA $8 \mathrm{~S}$ & 3 & \multirow{4}{*}{ Bk 32-M } & SMA $8 \mathrm{~S}$ & 3 \\
\hline & & $\mathrm{AC} 22 \mathrm{BS}$ & 8 & & AC $22 \mathrm{BS}+30 \% \mathrm{RAP}$ & 8 \\
\hline & & AC 32 TS & 14 & & AC 32 TS $+60 \%$ RAP & 14 \\
\hline & & Unbound & 45 & & Unbound & 45 \\
\hline \multirow{14}{*}{$\begin{array}{l}\text { Main Access } \\
\text { Roads }\end{array}$} & \multirow{4}{*}{$\mathrm{Bk} 3.2-\mathrm{T} 1$} & SMA $8 \mathrm{~S}$ & 3 & \multirow{4}{*}{ Bk 3.2-M1 } & SMA $8 \mathrm{~S}$ & 3 \\
\hline & & $\mathrm{AC} 16 \mathrm{BS}$ & 5 & & $\mathrm{AC} 16 \mathrm{BS}+30 \% \mathrm{RAP}$ & 5 \\
\hline & & AC 22 TS & 10 & & AC 22 TS + 30\% RAP & 10 \\
\hline & & Unbound & 45 & & Unbound & 45 \\
\hline & \multirow{10}{*}{$\mathrm{Bk} 3.2-\mathrm{T} 2$} & OR & & \multirow{6}{*}{ Bk 3.2-M2 } & OR & \\
\hline & & AC 8 DS & 3 & & AC 8 DS + 50\% RAP & 3 \\
\hline & & $\mathrm{AC} 16 \mathrm{BS}$ & 5 & & $\mathrm{AC} 16 \mathrm{BS}+30 \% \mathrm{RAP}$ & 5 \\
\hline & & AC 22 TS & 10 & & AC 22 TS + 30\% RAP & 10 \\
\hline & & Unbound & 45 & & Unbound & 45 \\
\hline & & & & & OR & \\
\hline & & & & \multirow{4}{*}{$\mathrm{Bk} 3.2-\mathrm{M} 3$} & AC 8 DS + 50\% RAP & 3 \\
\hline & & & & & $\mathrm{AC} 16 \mathrm{BS}+50 \% \mathrm{RAP}$ & 5 \\
\hline & & & & & AC 22 TS & 10 \\
\hline & & & & & Unbound & 45 \\
\hline \multirow{7}{*}{$\begin{array}{l}\text { Residential } \\
\text { Roads }\end{array}$} & \multirow{4}{*}{ Bk 1.0-T } & $\mathrm{AC} 8 \mathrm{DN}$ & 3 & \multirow{7}{*}{ Bk 1.0-M } & AC 8 DS + 50\% RAP & 3 \\
\hline & & $\mathrm{AC} 22 \mathrm{TN}+40 \% \mathrm{RAP}$ & 10 & & $\mathrm{AC} 22 \mathrm{TN}+40 \% \mathrm{RAP}$ & 10 \\
\hline & & Unbound & 45 & & Unbound & 45 \\
\hline & & OR & & & & Surface Layer \\
\hline & \multirow{3}{*}{ Bk 0.3-T } & AC 8 DN & 3 & & & Binder Layer \\
\hline & & $\mathrm{AC} 22 \mathrm{TN}+40 \% \mathrm{RAP}$ & 8 & & & Base Layer \\
\hline & & Unbound & 39 & & & Unbound Layer \\
\hline
\end{tabular}

\subsection{Asphalt Production}

The asphalt mixtures were produced using primary raw materials, such as bitumen, diabase aggregates, and limestone as a filler, as well as using RAP. The bitumen can vary according to the mixture type: stone mastic asphalt (SMA) mixtures contain polymermodified bitumen (PMB), whereas asphalt concrete (AC) is composed of 50/70 bitumen.

The asphalt plant located in Münster (Germany) is defined as batch-mixing plant and follows the cold-recycling method to produce asphalt mixtures with RAP.

The RAP is procured from pavements milled in Münster and is transported to the asphalt plant for further application in asphalt mixtures after initial treatment (crushing, sieving, and separation).

The asphalt plant produces approximately 150,000 tons of asphalt mixtures and $50,000-80,000$ tons of RAP per year. Approximately $98 \%$ of the heating energy is obtained from coal and $2 \%$ from light fuel oil. The overall energy consumption of the asphalt plant is presented in Table 2.

Table 2. Annual energy demands of the asphalt plant.

\begin{tabular}{ccl}
\hline & Inputs of Asphalt Production & \\
\hline Energy & 667,500 & $\mathrm{kWh} /$ year \\
Heat (Light fuel oil) & 118,500 & $\mathrm{kWh} /$ year \\
Heat (Coal) & $11,551,500$ & $\mathrm{kWh} /$ year \\
Diesel & 355,500 & $\mathrm{kWh} /$ year \\
\hline
\end{tabular}

Because it is not possible to determine the individual energy consumption for the production of asphalt mixtures or for that of RAP, the energy required to produce each asphalt mixture was calculated using Equation (1) [24,25]. Additional information, such as the asphalt mixture recipe, densities, mixing temperatures, and other variables used in the 
aforementioned formula are available in the supplementary material (Tables S1-S3) and in a paper published by Siverio Lima et al. (2020) [12].

$T E=\left[\begin{array}{c}\sum_{i=0}^{M} m_{i} \times C_{i} \times\left(t_{\text {mix }}-t_{0}\right)+m_{\text {bit }} \times C_{\text {bit }} \times\left(t_{\text {mix }}-t_{0}\right)+m_{\text {rap }} \times C_{\text {rap }} \times\left(t_{\text {mix }}-t_{0}\right)+ \\ \sum_{i=0}^{M} m_{i} \times W_{i} \times C_{w} \times\left(100-t_{0}\right)+L_{v} \times \sum_{i=0}^{M} m_{i} \times W_{i}+\sum_{i=0}^{M} m_{i} \times W_{i} \times C_{\text {vap }} \times\left(t_{\text {mix }}-100\right)\end{array}\right] \times(1+C L)$

where:

$C_{b i t}:$ Specific heat coefficient of bitumen $(50 / 70)-\mathrm{kJ} / \mathrm{kg} \cdot{ }^{\circ} \mathrm{C}$

$C_{i}$ : Specific heat coefficient of aggregates- $\mathrm{kJ} / \mathrm{kg} \cdot{ }^{\circ} \mathrm{C}$

$C_{w}$ : Specific heat coefficient of water $\left(10^{\circ} \mathrm{C}\right)-\mathrm{kJ} / \mathrm{kg} \cdot{ }^{\circ} \mathrm{C}$

$C_{\text {vap }}$ : Specific heat coefficient of water vapor- $\mathrm{kJ} / \mathrm{kg} \cdot{ }^{\circ} \mathrm{C}$

$C_{R A P}:$ Specific heat coefficient of $\mathrm{RAP}-\mathrm{kJ} / \mathrm{kg} \cdot{ }^{\circ} \mathrm{C}$

$W_{i}$ : Water content of aggregates-\%

$L_{v}$ : Latent heat of vaporization of water $-\mathrm{kJ} / \mathrm{kg}$

$C L$ : Casing loss factor- $\%$

$t_{0}$ : Ambient temperature- ${ }^{\circ} \mathrm{C}$

$t_{\text {mix }}$ : Maximum temperature of aggregates and $\mathrm{RAP}-{ }^{\circ} \mathrm{C}$

$m_{b i t}:$ Mass of bitumen- $\mathrm{kg}$

$m_{i}$ : $\quad$ Mass of aggregates and filler $-\mathrm{kg}$

$m_{R A P}:$ Mass of RAP $-\mathrm{kg}$

M: Materials

\subsection{Construction and Deconstruction Processes}

As mentioned earlier, Münster's urban pavements contain three (RSDTs) or four (MRs and MARs) layers, among which one is an unbound layer (subbase), and the others are built using asphalt materials.

The first stage of pavement construction involves spreading the gravel with a bulldozer to build the unbound layer. Subsequently, the two rolling processes with a single drum are performed, followed by a compacting process with a vibration plate to complete the construction of the subbase layer.

The construction of new asphalt layers begins with the spraying of a bituminous emulsion on the underlying layer to improve the inter-layer adhesion. Thereafter, the hot asphalt mixture is discharged and distributed. After the asphalt layer is placed, two rolling processes are executed with a single drum, and the asphalt layer is then compacted using a vibration plate.

Depending on the maintenance strategy, the pavement layers can be replaced separately or together. The asphalt layers are deconstructed with a mill cutter, and a hydraulic digger loads the unbound subbase onto a transport lorry. Figure 1 shows all the processes necessary for the construction and deconstruction of pavements.

The machines used to construct and deconstruct pavements are listed in Table 3. The specifications were obtained from the literature [26] to facilitate the modeling process.

Table 3. Machines used during the construction and deconstruction stages [26].

\begin{tabular}{ccc}
\hline Process & Machine Type & Model \\
\hline Spraying bitumen emulsion & Bitumen sprayer on a lorry & Atlas AE 6000 \\
Paving & Asphalt paver & CAT AP 555 E \\
Rolling & Single Drum Smooth-Vibration compactor & CAT CS 74 C \\
Compacting & Vibration plate & Weber CR 10 \\
Distribution & Bulldozer & CAT D5K LGP \\
Milling & Mill cutter & Wirtgen W 200 \\
Loading & Hydraulic digger & CAT 345 D \\
\hline
\end{tabular}




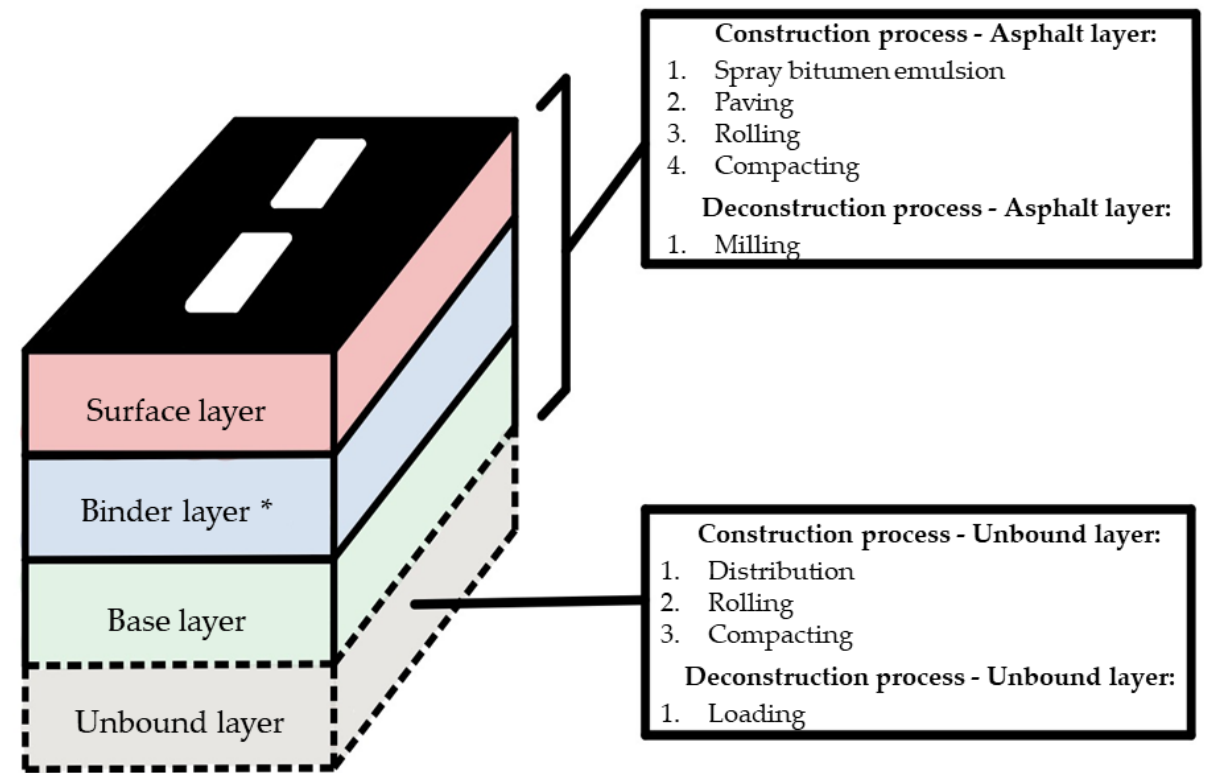

*Applied only to main roads and main access roads

Figure 1. Pavement construction and deconstruction processes.

\subsection{Maintenance Strategies}

The maintenance routine adopted by the city of Münster varies according to the pavement structure and the strategy defined to keep the pavement in acceptable condition, as shown in Table 4. In general, there are three main phases of pavement maintenance:

1. Deconstruction and construction of the surface layer (M1);

2. Deconstruction and construction of the surface layer and following layer, which can be either the binder layer for Bk 32 and Bk 3.2 structures or the base layer for Bk 1.0 and Bk 0.3 structures (M2);

3. Total deconstruction and construction of the pavement (M3).

Table 4. Maintenance strategies for pavements in Münster.

\begin{tabular}{|c|c|c|c|c|c|c|c|c|c|c|}
\hline \multirow{3}{*}{ Classification } & \multirow{3}{*}{$\begin{array}{l}\text { Load } \\
\text { Class }\end{array}$} & \multirow{3}{*}{$\begin{array}{l}\text { Pavement } \\
\text { Structure }\end{array}$} & \multicolumn{8}{|c|}{ Maintenance Strategies (Years) } \\
\hline & & & \multicolumn{5}{|c|}{ A } & \multicolumn{3}{|c|}{ B } \\
\hline & & & M1 & M2 & M3 & M4 & & M1 & M2 & M3 \\
\hline \multirow{4}{*}{ Main roads } & \multirow{4}{*}{ Bk 32} & Surface layer & 15 & 30 & 40 & & \multirow{14}{*}{ or } & & & \\
\hline & & Binder layer & & 30 & 40 & & & & & \\
\hline & & Base layer & & & 40 & & & & & \\
\hline & & Unbound & & & 40 & & & & & \\
\hline \multirow{4}{*}{$\begin{array}{l}\text { Main access } \\
\text { roads }\end{array}$} & \multirow{4}{*}{ Bk 3.2} & Surface layer & 15 & 30 & 40 & 50 & & 20 & 35 & 50 \\
\hline & & Binder layer & & 30 & & 50 & & & 35 & 50 \\
\hline & & Base layer & & & & 50 & & & & 50 \\
\hline & & Unbound & & & & 50 & & & & 50 \\
\hline \multirow{6}{*}{$\begin{array}{l}\text { Residential } \\
\text { roads }\end{array}$} & \multirow{3}{*}{ Bk 1.0} & Surface layer & 40 & 80 & & & & 20 & 40 & 60 \\
\hline & & Base layer & & 80 & & & & & 40 & 60 \\
\hline & & Unbound & & 80 & & & & & & 60 \\
\hline & \multirow{3}{*}{ Bk 0.3} & Surface layer & 40 & 60 & 80 & & & & & \\
\hline & & Base layer & & 60 & 80 & & & & & \\
\hline & & Unbound & & & 80 & & & & & \\
\hline
\end{tabular}

Administrators in Münster use one maintenance strategy for Bk 32 and Bk 0.3 structures and one of two maintenance strategies for Bk 3.2 and $\mathrm{Bk} 1.0$ structures, referred to herein as " $\mathrm{A}$ " and " $\mathrm{B}$ ".

To understand the impacts of the pavement strategies over time, different lifetimes were simulated in this study: 20, 50, 80, and 100 years. 


\section{Life Cycle Assessment}

\subsection{Goal}

This study was conducted to support the decision-making process used by the Münster authorities, based on an analysis of the environmental potentials of the urban pavements. The main goal of this study was to assess the environmental impacts of the asphalt materials, pavement structures, and road maintenance strategies adopted in Münster considering lifetimes of 20,50, 80, and 100 years.

\subsection{Scope of the Study}

\subsubsection{System Boundaries}

The "cradle-to-cradle" approach with a "closed-loop recycling" method was employed in this study. Therefore, we assumed that $100 \%$ of the road materials obtained from the deconstruction were recycled within the same production chain and used in the production of new asphalt materials.

All life cycle phases, from raw material acquisition (A1) to the recycling process (C3), were considered in the analysis, except for the "use phase" processes related to vehicle operation, lighting, road cleaning, etc. In addition, services such as maintenance, repair, replacement, and refurbishment of pavements were considered.

The primary raw materials (diabase aggregates, limestone as filler, and bitumen) are procured from different suppliers located across Europe and transported to the asphalt plant to proceed with the manufacturing of asphalt mixtures.

The secondary raw material (RAP), originating from the milling of Münster pavements, is subsequently transported to the asphalt plant for treatment before being added into the asphalt mixtures. Because the asphalt plant is the initial and final destination of the RAP, no additional transportation is required between these steps. Further details, such as the cut-off point, are explained in Section 3.2.3.

The asphalt mixtures produced in the asphalt plant are transported to the construction site to build the pavements. Depending on the project design, classification, and maintenance strategy adopted, the road pavements are partially or entirely deconstructed during maintenance. Figure 2 shows the system boundaries and phases considered in the analysis.

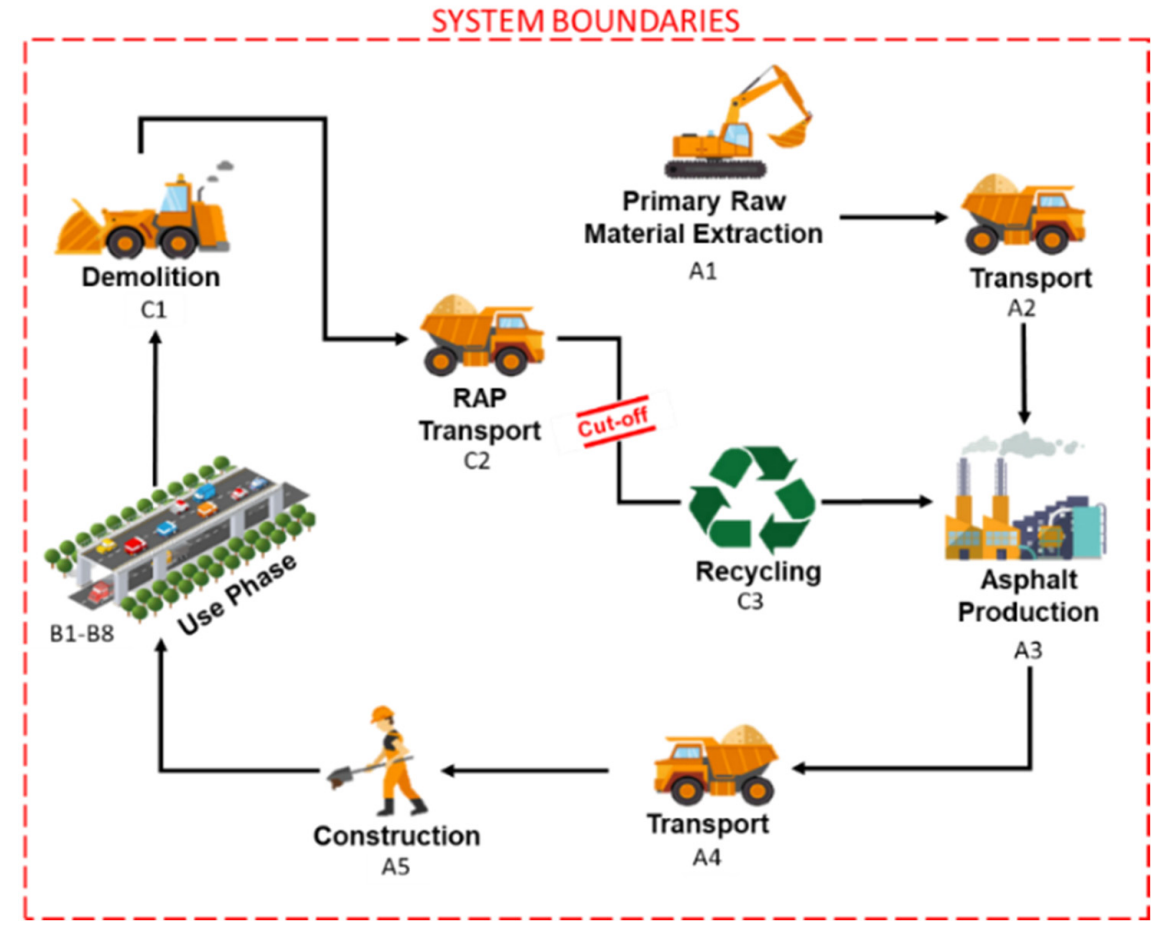

Figure 2. System boundaries of the study. 
The terminology used to describe the life cycle stages in Figure 2 is defined in the EN 15804:2018 standard [27], as presented below:

- A1: raw material supply;

- A2: transport of raw material to the manufacturer;

- A3: manufacture of the asphalt mixtures at the asphalt plant;

- A4: transport of asphalt mixtures to the construction site;

- A5: construction of pavements;

- B1-B8: use, maintenance, repair, and replacement of asphalt layers;

- C1: demolition of pavement;

- C2: transport of milled asphalt pavement to the asphalt plant;

- C3: waste processing operations for reuse, recovery, or recycling (RAP production).

\subsubsection{Functional Unit}

The functional unit used in this study was $1 \mathrm{~m}^{2}$ of road pavement.

\subsubsection{RAP: Allocation and Closed-Loop Recycling}

In this study, the RAP was considered as a secondary raw material rather than the end of life of the pavement. Thus, the environmental loads of the treatments performed on the RAP, such as crushing, sieving, and separation, were attributed only to the asphalt mixtures containing RAP.

Therefore, the cut-off point was set between the transportation of the milled pavement to the asphalt plant and the production of RAP.

Considering RAP as a secondary raw material implies reducing the use of the primary raw material. Thereby, all environmental loads involved in RAP production (crushing, sieving, and separation) are incorporated into the system, creating a closed loop of recycling. Meanwhile, the system boundaries of asphalt materials without RAP include all environmental loads associated with the use of primary raw materials until the deconstruction process and transportation back to the asphalt plant.

\subsection{Life Cycle Inventory (LCI)}

The primary data associated with the road network (i.e., pavement design) and the production of asphalt mixtures, such as raw material suppliers, recipes, and amounts of energy and water consumption, were collected through questionnaires answered by the asphalt producers and the road department of Münster.

The distances to transport either the primary (205 km for aggregates, $112 \mathrm{~km}$ for bitumen, and $205 \mathrm{~km}$ for filler) or secondary raw materials ( $25 \mathrm{~km}$ for RAP) were calculated considering the asphalt plant as the final destination. The materials are transported from the origin to the asphalt plant by a five-axle lorry vehicle (EURO 6) [28], that weighs around 14 tons and has a maximum load capacity of 26 tons. The fuel consumption varies from 0.18 $\mathrm{L}$ of biodiesel per kilometer when empty to $0.32 \mathrm{~L}$ of fuel per kilometer when fully loaded.

The relevant input and output data that the producer could not provide were obtained from the literature $[13,26,29]$. Some variables, such as the specific heat coefficient of materials and latent heat of vaporization of water of Equation (1) [24,25], were obtained from Santos et al. [25].

Information regarding the machines used for the construction and deconstruction processes was sourced from Gschösser (2011) [26] and modeled based on producer data [30-34], as shown in the supplementary material (Tables S4 and S5).

The mineral aggregates were modeled using the dataset for "crushed gravel", while "crushed limestone" was used as a filler dataset to create the asphalt mixtures. Because the required input data were not accessible, the RAP production (crushing, sieving, and separation) was modeled based on the "limestone production, crushed, for the mill" dataset available in Ecoinvent. Owing to the limitations of the software (which provides only an average input), all asphalt mixtures were modeled using the same dataset for bitumen. 
All the inputs and outputs were modeled using SimaPro 9.0 (PRé Sustainability: Amersfoort, The Netherlands) [35] and the Ecoinvent 3.5 database (Ecoinvent: Zurich, Switzerland) [36]. The LCIs for all phases of the pavement's lifetime are listed in the supplementary material (Tables S1-S10).

\subsection{Life Cycle Impact Assessment}

To assess the environmental impact of road pavements, we adopted the GWP ( $\mathrm{kg}$ $\mathrm{CO}_{2}$ equivalent) indicator used in the Environmental Product Declarations (EPD 2018) [37] method and the non-renewable cumulative energy demand (nr-CED) parameters, which is based on the Cumulative Energy Demand method V1.11 in Ecoinvent version 2.0 [36] and is presented in MJ equivalent.

A Monte Carlo simulation was performed to verify the reliability of the environmental impact results using SimaPro software. In LCA, the uncertainty comes from the input data collected, which can be described by a specific distribution characterized by a standard deviation [38]. The standard deviation of each life cycle inventory entry is calculated by using the pedigree matrix method proposed by Ecoinvent $[36,39]$, which is based on six factors (i.e., reliability, completeness, temporal correlation, geographical correlation, technological correlation, and sample size) [36,39]. Hence, a random value of uncertainty based on the reliability given by the data collection is specified to each inventory entry. The values attributed might vary from 1 to 5 and can be see within the supplementary material (Tables S1 and S4-S9). The calculations use a 95\% confidence interval and perform 1000 runs to obtain an a probability distribution for each scenario [39].

In order to verify the impact of uncertainty, nine Monte Carlo simulations were performed comparing the GWP and nr-CED results of two 100 years lifetime pavement structures cases. The comparisons were defined taking into account the best- and worstcase scenario presented within each category.

\section{Results}

The environmental impacts in terms of GWP and nr-CED per square meter of road pavement are shown in absolute numbers in the supplementary material (Table S11).

Figures 3 and 4 show the overall environmental impact of the different pavement structures in terms of nr-CED and GWP over the pavement lifetime. In general, the higher the traffic load on the pavement, the higher the environmental impact.

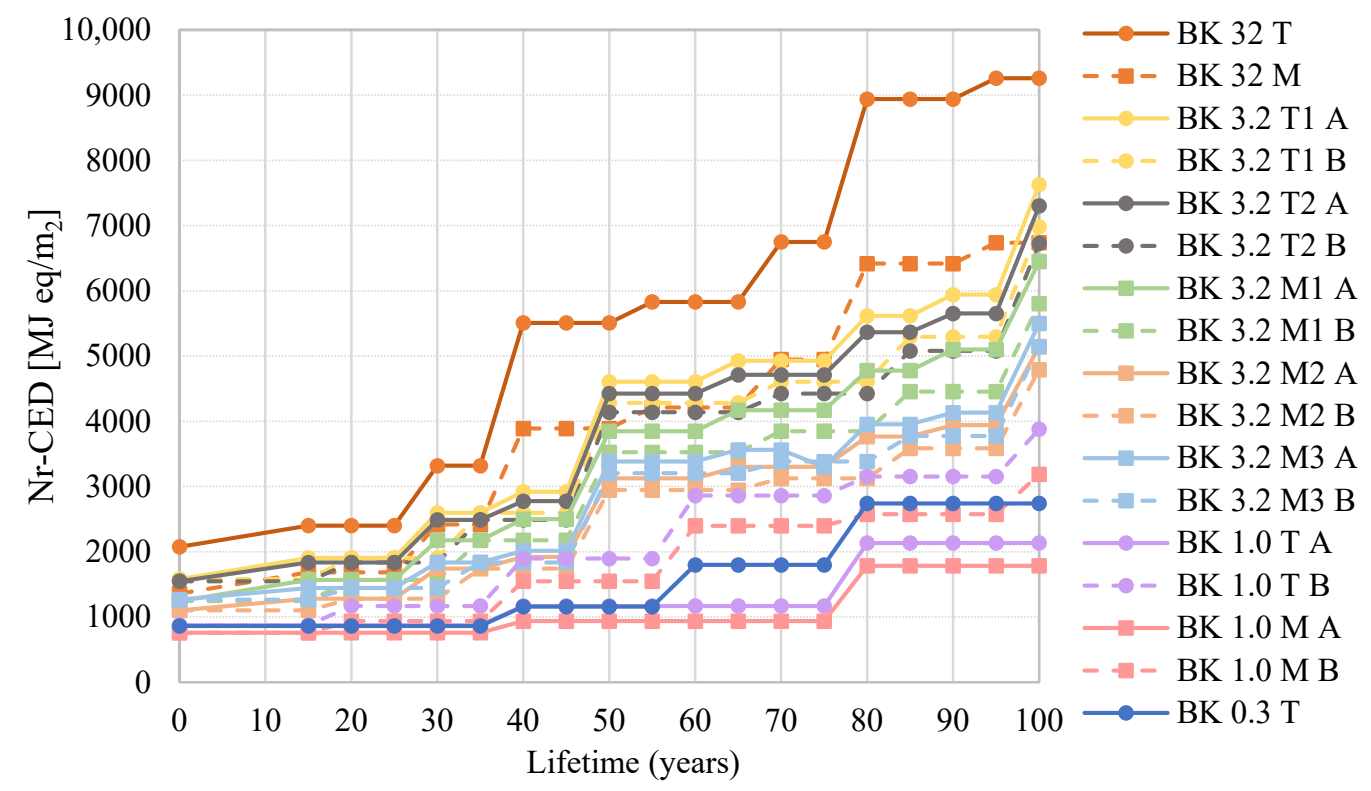

Figure 3. Nr-CED results over the years. 


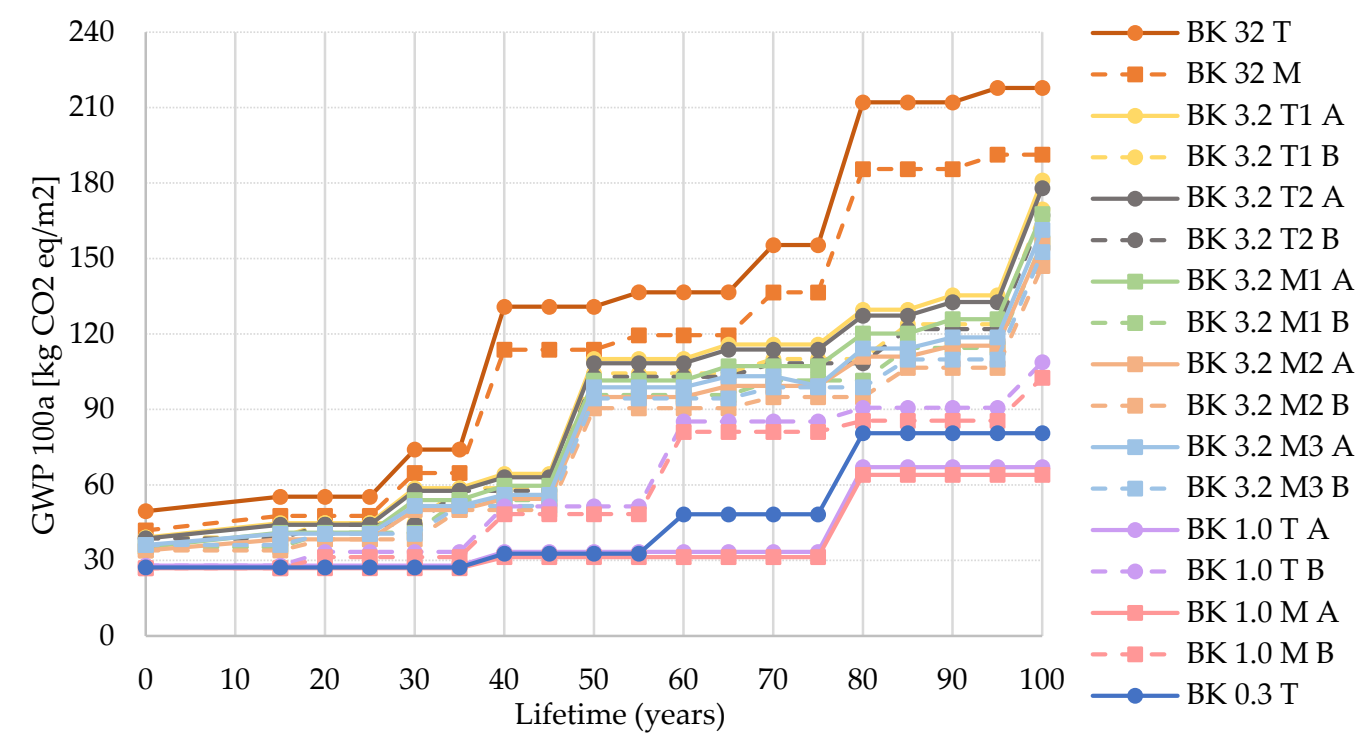

Figure 4. GWP results over the years.

The "modified" structures exhibited lower environmental impacts than the "traditional" structures did, in terms of both indicators and for all lifetimes evaluated. Therefore, using higher contents of RAP to produce asphalt mixtures for road pavement layers potentially reduces the environmental impacts (GWP and nr-CED) of pavement construction over the lifetime of the pavement.

The difference between the environmental impacts of the "traditional" and "modified" structures is emphasized with respect to the lifetime: the longer the lifetime, the larger the difference between the "traditional" and "modified" structures.

For the lifetime of 20 years, strategies " $A$ " and " $B$ " presented similar impacts for the Bk 3.2 structures in terms of nr-CED and GWP. In contrast, for Bk $1.0 \mathrm{~T}$, increases of $25 \%$ in nr-CED and 16\% in GWP were observed upon changing the maintenance strategy from " $\mathrm{A}$ " to " $\mathrm{B}$ ", while for the modified structure (Bk 1.0 M), an increase of $19 \%$ in $\mathrm{nr}-\mathrm{CED}$ and $14 \%$ in GWP was observed.

For the lifetime of 50 years, there was a larger difference between the impacts of MARs (Bk 3.2) and residential pavement structures (Bk 1.0) because of the maintenance strategy employed for the former. Unlike for the 20-year lifetime, there were only slight differences between the "traditional" and "modified" Bk 3.2 structures and between strategies "A" and "B".

For the lifetime of 80 years, maintenance strategy "B" used in Bk 3.2 structures, showed reduced impacts in terms of both indicators; average reductions of $17 \%$ in nr-CED and $15 \%$ in GWP were observed when strategy " $\mathrm{A}$ " was used for the same structures. The discrepancies between the "traditional" and "modified" structures and between strategies " $\mathrm{A}$ " and " $\mathrm{B}$ " are amplified due to the frequency of interventions in each case.

For the lifetimes of 50 and 100 years, the differences between the impacts associated with strategies " $\mathrm{A}$ " and " $\mathrm{B}$ " decreased by an average of 7.5\% in nr-CED and 5.5\% in GWP for the MAR structures (Bk 3.2).

For Bk 1.0 pavements, strategy " $\mathrm{A}$ " leads to potentially lower environmental impacts in terms of GWP and nr-CED than strategy " $B$ " does over 20, 50, 80, and 100 years. Both $\mathrm{Bk} 1.0 \mathrm{~T}$ " $\mathrm{A}$ " and $\mathrm{Bk} 1.0 \mathrm{M}$ " $\mathrm{A}$ " structures showed reduced impacts compared to the $\mathrm{Bk}$ 0.3 structure. The difference is amplified over the years, and it can be observed that Bk 1.0 $\mathrm{T}$ " $\mathrm{A}$ " had the lowest environmental impact among the traditional structures. Therefore, for longer service lifetimes, it is potentially better to construct $\mathrm{Bk} 1.0 \mathrm{~T}$ pavements using maintenance strategy " $\mathrm{A}$ " than to construct Bk 0.3 structures in residential roads. The use of Bk 1.0 pavement structures in Bk 0.3 traffic load areas would reduce the environmental impacts of residential roads as the pavements would last longer. 
Figure 3 shows that the environmental impact of Bk 32 T structures, in terms of nr-CED in year zero, was $274 \%$ higher than that of the lowest-impact structure (Bk $1.0 \mathrm{M}^{\text {" }} \mathrm{A}^{\prime \prime}$ ). After 100 years, the difference between the impacts grew to 518\%. Figure 4 shows that compared with Bk 1.0 M "A", the Bk $32 \mathrm{~T}$ structure emitted $184 \%$ more $\mathrm{CO}_{2}$ in year zero and $340 \%$ more $\mathrm{CO}_{2}$ after 100 years. The gap is due to the overall amount of material used and the constant rehabilitation procedures required for pavements with high traffic loads (i.e., Bk $32 \mathrm{~T}$ ).

Using higher amounts of RAP to construct Bk 32 structures reduced the emission of $\mathrm{CO}_{2}$ by $12 \%$ and the value of nr-CED by $27 \%$ over 100 years. The Bk $32 \mathrm{M}$ structure presented lower or similar impacts in terms of nr-CED when compared with Bk $3.2 \mathrm{~T} 1$ " $\mathrm{A}$ ", Bk 3.2 T1 “B”, Bk 3.2 T2 “A”, and Bk 3.2 T2 "B" structures.

Initially, all the MAR structures exhibited similar impacts. The longer the time, the higher the impact gap between the structures. The Bk 3.2 M2 "B" structure presented the lowest environmental impacts in terms of both the indicators, whereas Bk 3.2 T1 " $\mathrm{A}^{\text {" }}$ exhibited the largest impacts. After 100 years, Bk $3.2 \mathrm{~T} 1$ " $\mathrm{A}$ " had a 37\% larger impact in terms of nr-CED and 19\% higher $\mathrm{CO}_{2}$ emissions than Bk 3.2 M2 "B" did.

Among the residential pavement structures, the reduction in impact after 100 years was approximately $54 \%$ in terms of nr-CED and $41 \%$ in terms of GWP, when comparing the highest-impact structure (Bk 1.0 T "B") with the lowest-impact one (Bk 1.0 M " $\left.\mathrm{A}^{\prime \prime}\right)$. Bk 0.3 showed similar environmental impacts as $\mathrm{Bk} 1.0 \mathrm{~T}$ " $\mathrm{A}$ " and $\mathrm{Bk} 1.0 \mathrm{M}$ " $\mathrm{A}$ " did until the 55th year; thereafter, the interventions and the deconstruction and construction of the surface and base layers increased the impact gap between the structures.

\subsection{Impact Contribution per Category}

Figure 5 shows the average impact contribution per category. Because the asphalt plant provided only the total amount of energy consumed, instead of individual data the "production" category comprised both operations: the impact of the asphalt mixture production as well as that of RAP processing (crushing, sieving, and separation).

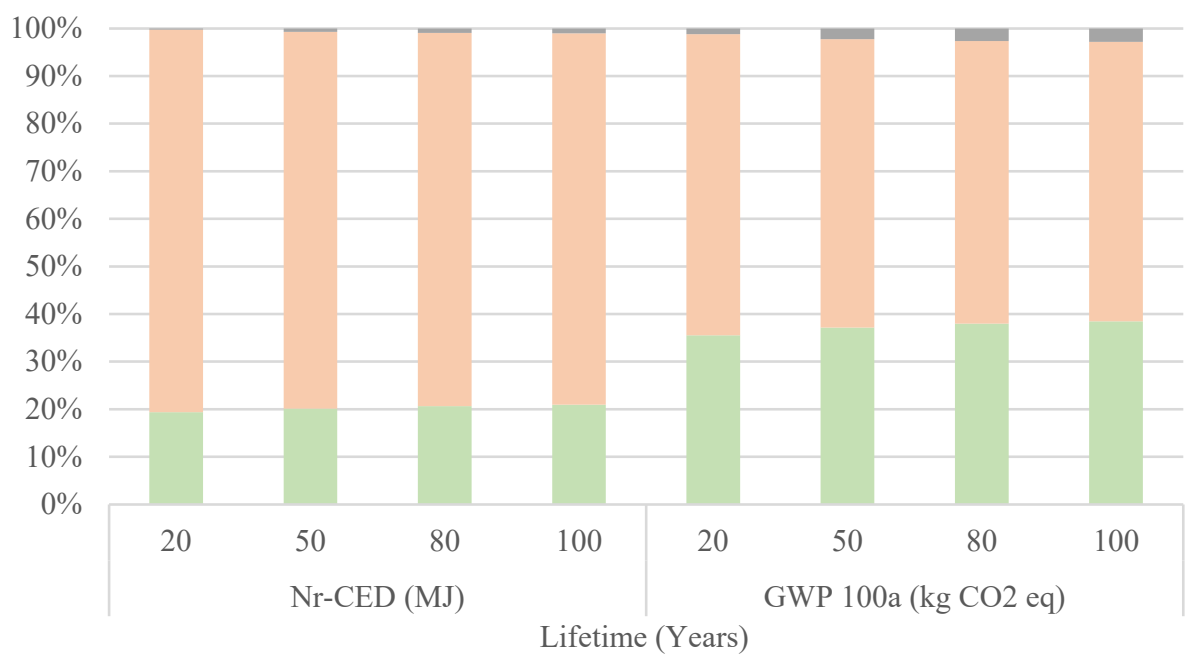

-CONSTRUCTION AND DECONSTRUCTION $\backsim$ PRODUCTION $₫$ TRANSPORTATION

Figure 5. Environmental impacts divided into categories.

The "production" and "transportation" processes are the main contributors to environmental impact in terms of nr-CED and GWP. The "production" process is responsible for nearly $78 \%$ of the impact in terms of nr-CED and 55\% in terms of GWP, due to the energy demand for heating the materials and the gas emissions during asphalt production.

In contrast, "transportation" contributes $20 \%$ in terms of nr-CED and $36 \%$ in terms of GWP; this impact is mainly due to the transportation distances covered by the aggregates $(205 \mathrm{~km})$, bitumen $(112 \mathrm{~km})$, and filler $(205 \mathrm{~km})$ from the suppliers to the asphalt 
plant. Therefore, the "modified" pavement structures with higher amounts of RAP and modeled to perform similar to the "traditional" structures are most likely to have lower environmental impacts due to the reduced amount of virgin raw material used and the shorter transportation distances for the RAP $(25 \mathrm{~km})$.

Only a small share of the impact (1-3\%) is attributed to the "construction and deconstruction" processes.

\subsection{Monte Carlo Analysis}

Figure 6 compares the two structures and shows the probability of one structure exhibiting higher $(\mathrm{A} \geq \mathrm{B})$ or lower $(\mathrm{A}<\mathrm{B})$ environmental impacts than the other over an analysis period of 100 years.

100 years
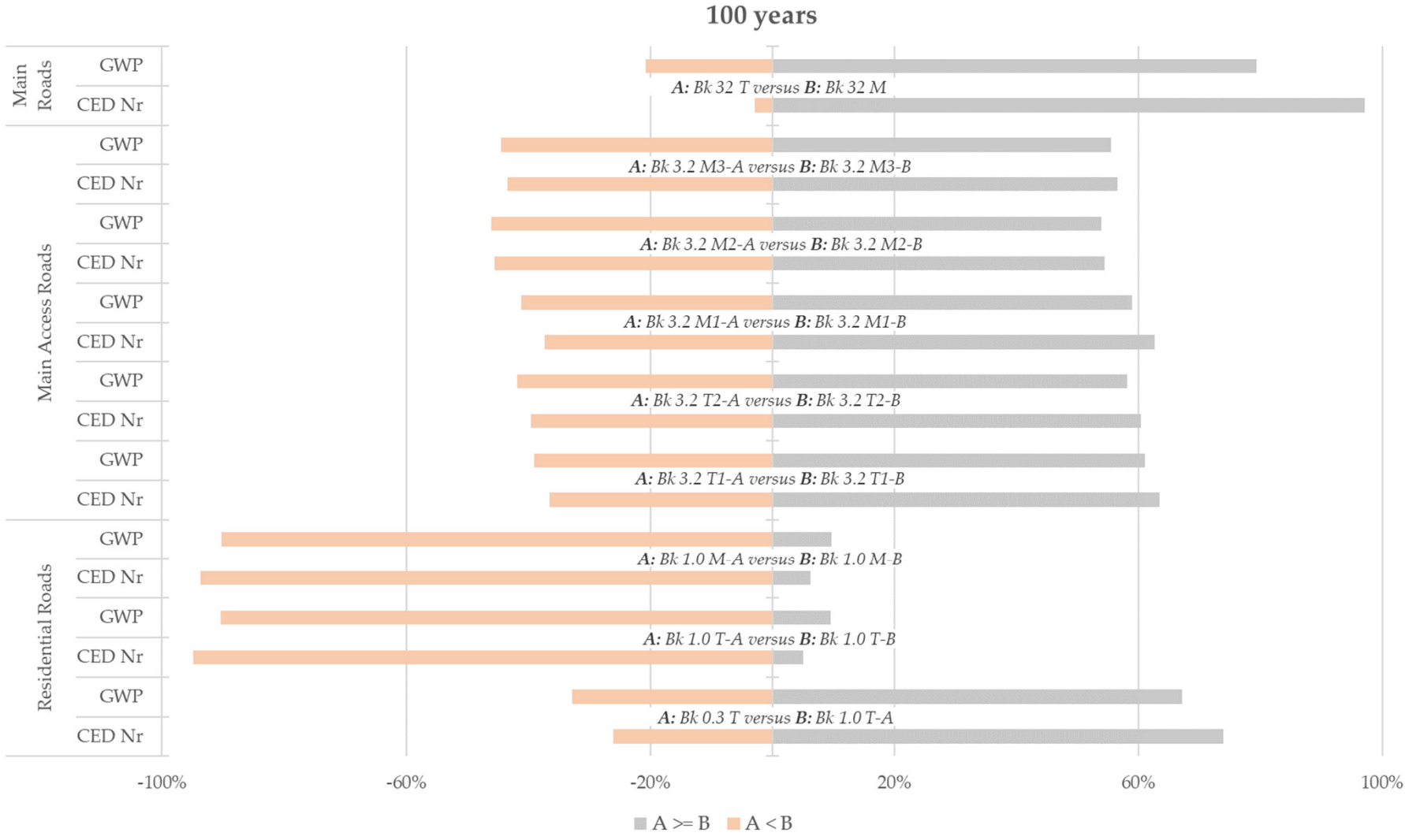

Figure 6. Monte Carlo simulation: 100 years.

The first analysis shows that "traditional" Bk 32 structures (Bk $32 \mathrm{~T}$ ) are more likely to have higher environmental impacts than their "modified" counterparts (Bk $32 \mathrm{M})$. In this case, the maintenance strategies over the years are equal and the reduction in impact is due to the higher amount of RAP within the "modified" structure.

A comparison between maintenance strategies " $\mathrm{A}$ " and " $\mathrm{B}$ " of the Main Access Road pavements shows a slight probability of strategy " $\mathrm{B}$ " having a lower environmental impact than strategy " $\mathrm{A}$ " for Bk 3.2 structures. The reduced impact presented by the strategy " $\mathrm{B}$ " is related to the interval and periodicity of interventions defined: " $\mathrm{B}$ " demands the changing the top layer after 20 years and the following layers after 15 years, while the " $\mathrm{A}$ " requires the first intervention after 15 years and four interventions during the entire pavement lifespan.

The comparison between the strategies for $\mathrm{Bk} 1.0$ structures shows a higher probability of " $\mathrm{A}$ " having minor impacts in terms of both indicators due to the reduced demand of interventions (2) over the entire life time of the pavement in comparison with " $B$ " (3).

Regarding the use of $\mathrm{Bk} 0.3$ or $\mathrm{Bk} 1.0 \mathrm{~T}$ " $\mathrm{A}$ " structures, Figure 6 shows that $\mathrm{Bk} 0.3$ is more likely to have higher impacts than $\mathrm{Bk} 1.0 \mathrm{~T}$ " $\mathrm{A}$ " is over 100 years. 


\section{Conclusions}

This study aimed to assist cities to embrace the Agenda 2030 and enhance the environmental performance of urban road networks by assessing the life cycle of urban pavements and the maintenance strategies adopted by administrators in Münster (Germany). Based on the results, the following conclusions were drawn.

- Combining layers containing the largest possible amount of reclaimed asphalt pavement (RAP) might reduce potential environmental impacts in terms of non-renewable cumulative energy demand (nr-CED) and global warming potential (GWP);

- The longer the simulated service life, the greater the difference in environmental impact between the "traditional" and "modified" structures;

- In general, the higher the traffic load on roads, the greater the environmental impact;

- The higher the reconstruction interval and lifespan of pavements, the lower the environmental impact;

- In residential areas, it might be recommended to build stronger structures and reduce the maintenance interval than the opposite;

- Approximately $98 \%$ of the environmental impacts over the pavement life cycle is due to the production of asphalt mixtures and materials transportation (i.e., raw materials, asphalt mixtures, and reclaimed asphalt pavement);

- Construction and deconstruction have a negligible influence on the overall impact of pavements during the service life;

- Maintenance strategies can strongly influence the environmental impact of urban roads. Therefore, pavement design, service life, and maintenance periodicity should be carefully evaluated.

This study showed that using reclaimed asphalt pavement to compose asphalt mixtures can potentially mitigate the environmental impacts of pavements over their lifetime because of the reduced use of raw materials, which reduces transportation distances. The results showed that the addition of 30\% RAP in the binder layer and $60 \%$ RAP in the base layer within the pavement structures of main road categories might save $2521 \mathrm{MJ}$ of energy and the emission of $26.5 \mathrm{~kg}$ of $\mathrm{CO}_{2}$ equivalent over 100 years per square meter of pavement built.

Considering the worst- and best-case scenarios for each pavement category, it is estimated that the city of Münster could save $2235 \mathrm{MJ}$ of energy and around $40 \mathrm{~kg}$ of $\mathrm{CO}_{2}$ equivalent over 100 years per square meter of pavement by using the least impactful options to compose its road network. If applied across the entire road network of Münster, the emission savings could reach 376,000 tons of $\mathrm{CO}_{2}$ after 100 years: this represents $0.00087 \%$ of the current annual emissions worldwide, or $10 \%$ of the annual emissions in Iceland. In addition, the amount of energy saved could reach approximately $5662 \mathrm{GWh}$-enough to supply a year of energy in countries such as Latvia, Luxemburg, or Honduras.

This investigation considered that all asphalt mixtures and pavement structures perform equally and have similar lifetimes. Even though the Monte Carlo simulation was used, future studies should consider the individual surface and mechanical performance of pavements and their durability when evaluating the maintenance strategies.

The suggested "modified" pavement structures may not be suitable for application as they do not account for local regulations. Moreover, the "traditional" pavement structures modeled in this study represent the conditions of Münster and may not apply to other areas.

Finally, it was shown that pavements with longer service lives have lower environmental impacts. Nevertheless, it is essential to define the ideal time for intervention and to maintain pavements to be in acceptable condition. Failure to achieve this can compromise users' safety and well-being, increase the risk of accidents, generate more noise, increase vehicle fuel consumption, and exacerbate the environmental impact of the pavement.

Although this study analyzed Münster's road network, it is essential to state that the assessed data represent the reality of many cities around the world-especially European cities-and provides relevant input data to support further life cycle assessment analysis to be made by other institutions in the future. 
Supplementary Materials: The following are available online at https: / www.mdpi.com/article/ 10.3390/su132212487/s1: Table S1: Asphalt production; Table S2: Heating calculation; Table S3: Pavement structure; Table S4: Machinery; Table S5: Processes; Table S6: Full construction; Table S7: Partial construction; Table S8: Full deconstruction; Table S9: Partial deconstruction; Table S10: Maintenance strategies; Table S11: Results.

Author Contributions: All authors have contributed to the current paper. Conceptualization, M.S.S.L.; data collection, M.S.S.L., A.B.; software, M.S.S.L.; writing-original draft preparation, M.S.S.L., M.H., F.G., A.B., and C.Q.; supervision, project administration, funding acquisition, V.H., and F.G.; writing-review and editing, M.S.S.L., M.H., S.H., R.S., V.H., A.B., C.Q., and F.G. All authors have read and agreed to the published version of the manuscript.

Funding: This project received funding from the European Union's Horizon 2020 research and innovation program under the Marie Sklodowska-Curie grant No. 765057, project name SAFERUP!. Part of this study was supported by the Latvian Council of Science on the basis of the Cabinet of Ministers of the Republic of Latvia Regulation No.725 "Evaluation of Fundamental and Applied Research Projects and Administration of Finance" within the project: No. LZP-2018/1-0237 "Innovative use of industrial by-products for sustainable asphalt pavement mixtures".

Institutional Review Board Statement: Not applicable.

Informed Consent Statement: Not applicable.

Data Availability Statement: The data presented in this study are available in the supplementary material.

Acknowledgments: This study is part of the SAFERUP! Project, an innovative training network devoted to developing safe, accessible, and urban pavements. The authors appreciate the support provided by the Road Construction Department of Münster, as well as the company Oevermann (asphalt plant) for the collaboration. Special thanks to Maria Koordt and Stephan Gomolluch for their assistance.

Conflicts of Interest: The authors declare no conflict of interest.

\section{References}

1. United Nations, Sustainable Development Goals. Available online: https://sustainabledevelopment.un.org/?menu=1300 (accessed on 10 March 2020).

2. European Union. The EU in the World: 2020 Edition; Publications Office of the European Union: Luxembourg, 2020. Available online: https: / / ec.europa.eu/eurostat/documents/3217494/10934584/KS-EX-20-001-EN-N.pdf/8ac3b640-0c7e-65e2-9f79-d0 3f00169e17?t=1590936683000 (accessed on 9 March 2021).

3. European Commission. Transport Emissions: A European Strategy for Low-Emission Mobility. Available online: https:/ / ec.europa. eu/clima/policies/transport_en (accessed on 9 March 2021).

4. Llopis-Castelló, D.; García-Segura, T.; Montalbán-Domingo, L.; Sanz-Benlloch, A.; Pellicer, E. Influence of Pavement Structure, Traffic, and Weather on Urban Flexible Pavement Deterioration. Sustainability 2020, 12, 9717. [CrossRef]

5. Trupia, L.; Parry, T.; Neves, L.C.; Lo Presti, D. Rolling Resistance Contribution to a Road Pavement Life Cycle Carbon Footprint Analysis. Int. J. Life Cycle Assess. 2017, 22, 972-985. [CrossRef]

6. Plati, C. Sustainability Factors in Pavement Materials, Design, and Preservation Strategies: A Literature Review. Constr. Build. Mater. 2019, 211, 539-555. [CrossRef]

7. Praticò, F.G.; Anfosso-Lédée, F. Trends and Issues in Mitigating Traffic Noise Through Quiet Pavements. Procedia Soc. Behav. Sci. 2012, 53, 203-212. [CrossRef]

8. Praticò, F.G.; Vaiana, R.; Giunta, M.; Iuele, T.; Moro, A. Recycling Pems Back to Tlpas: Is That Possible Notwithstanding RAP Variability? Appl. Mech. Mater. 2012, 253-255, 376-384. [CrossRef]

9. Licitra, G.; Moro, A.; Teti, L.; Del Pizzo, A.; Bianco, F. Modelling of Acoustic Ageing of Rubberized Pavements. Appl. Acoustics 2019, 146, 237-245. [CrossRef]

10. Dumitrescu, L.; Maxineasa, S.G.; Simion, I.M.; Taranu, N.; Andrei, R.; Gavrilescu, M. Evaluation of the Environmental Impact of Road Pavements from a Life Cycle Perspective. Environ. Eng. Manag. J. 2014, 13, 449-455. [CrossRef]

11. EPA, Global Greenhouse Gas Emissions by Economic Sector. Available online: https:/ /www.epa.gov/ghgemissions/globalgreenhouse-gas-emissions-data (accessed on 15 March 2021).

12. Siverio Lima, M.S.; Hajibabaei, M.; Hesarkazzazi, S.; Sitzenfrei, R.; Buttgereit, A.; Queiroz, C.; Tautschnig, A.; Gschösser, F. Environmental Potentials of Asphalt Materials Applied to Urban Roads: Case Study of the City of Münster. Sustainability 2020, 12, 6113. [CrossRef] 
13. Gschösser, F.; Wallbaum, H.; Boesch, M.E. Life-Cycle Assessment of the Production of Swiss Road Materials. J. Mater. Civ. Eng. 2012, 24, 168-176. [CrossRef]

14. Liu, X.; Cui, Q.; Schwartz, C. Greenhouse Gas Emissions of Alternative Pavement Designs: Framework Development and Illustrative Application. J. Environ. Manag. 2014, 132, 313-322. [CrossRef] [PubMed]

15. Vidal, R.; Moliner, E.; Martínez, G.; Rubio, M.C. Life Cycle Assessment of Hot Mix Asphalt and Zeolite-Based Warm Mix Asphalt with Reclaimed Asphalt Pavement. Resour. Conserv. Recycl. 2013, 74, 101-114. [CrossRef]

16. Aurangzeb, Q.; Al-Qadi, I.L.; Ozer, H.; Yang, R. Hybrid Life Cycle Assessment for Asphalt Mixtures with High RAP Content. Resour. Conserv. Recycl. 2014, 83, 77-86. [CrossRef]

17. Stanković, J.C.; Mladenović, G.; Queiroz, C. Impact of $\mathrm{CO}_{2}$ Emissions on Low Volume Road Maintenance Policy: Case Study of Serbia. 2019. Available online: https://www.researchgate.net/publication/335832262_Impact_of_CO_2_Emissions_on_Low_ Volume_Road_Maintenance_Policy_Case_Study_of_Serbia (accessed on 9 March 2021).

18. CEN. EN 15643-5, Sustainability of Construction Works—Sustainability Assessment of Buildings and Civil Engineering Works: Part 5-Framework for the Assessment of Sustainability Performance of Civil Engineering Works; CEN: Brussels, Belgium, 2016.

19. ISO. ISO 14040, Environmental Management_Life Cycle Assessment_Principles and Framework; ISO: Geneva, Switzerland, 2006.

20. Trunzo, G.; Moretti, L.; D'Andrea, A. Life Cycle Analysis of Road Construction and Use. Sustainability 2019, 11, 377. [CrossRef]

21. Jiang, R.; Wu, C.; Song, Y.; Wu, P. Estimating Carbon Emissions from Road Use, Maintenance and Rehabilitation through a Hybrid Life Cycle Assessment Approach-A Case Study. J. Clean. Prod. 2020, 277, 123276. [CrossRef]

22. Mladenovic, G.; Cirilovic, J.; Queiroz, C. Optimization of Road Maintenance and Rehabilitation on Serbian Toll Roads; Transportation Research Board of the National Academies: Washington, DC, USA, 2011.

23. Richtlinien Für Die Standardisierung Des Oberbaus von Verkehrsflächen: Rsto 12; FGSV Verlag: Cologne, Germany, $2012 ;$ Volume 499.

24. Santos, J.; Bressi, S.; Cerezo, V.; Lo Presti, D.; Dauvergne, M. Life Cycle Assessment of Low Temperature Asphalt Mixtures for Road Pavement Surfaces: A Comparative Analysis. Resour. Conserv. Recycl. 2018, 138, 283-297. [CrossRef]

25. Santos, J.; Flintsch, G.; Ferreira, A. Environmental and Economic Assessment of Pavement Construction and Management Practices for Enhancing Pavement Sustainability. Resour. Conserv. Recycl. 2017, 116, 15-31. [CrossRef]

26. Gschösser, F. Environmental Assessment of Road Constructions: Life Cycle Assessment of Swiss Road Pavements and Accompanying Analysis of Construction and Maintenance Costs. Ph.D. Thesis, ETH Zurich, Zürich, Switzerland, 2011.

27. CEN. EN 15804, Sustainability of Construction Works—Environmental Product Declarations—Core Rules for the Product Category of Construction Products; CEN: Brussels, Belgium, 2018.

28. Commission Regulation (EU) 2016/646 of 20 April 2016 Amending Regulation (EC) No 692/2008 as Regards Emissions from Light Passenger and Commercial Vehicles (Euro 6). Available online: https://eur-lex.europa.eu/legal-content/EN/TXT/?uri= CELEX\%3A32016R0646 (accessed on 8 November 2021).

29. Gschösser, F.; Wallbaum, H. Life Cycle Assessment of Representative Swiss Road Pavements for National Roads with an Accompanying Life Cycle Cost Analysis. Environ. Sci. Technol. 2013, 47, 8453-8461. [CrossRef] [PubMed]

30. Caterpillar Inc. Caterpillar Performance Handbook; Caterpillar Inc.: Deerfield, IL, USA, 2010.

31. Lissmac. FS 31 D-Robust Lloor Cutter for the Roughest Building Site Use; Lissmac Machinenbau GmbH: Wurzach, Germany, 2010.

32. Weber. Bodenverdichter CR 10; Weber Maschinentechnik GmbH: Bad Laasphe, Germany, 2010.

33. Wirtgen Group. Technical Specification-Slipform Paver SP 1200; Wirtgen Group: Windhagen, Germany, 2010.

34. Wirtgen Group. Technical Specification-Cold Milling Machine W 200; Wirtgen Group: Windhagen, Germany, 2010.

35. PRé Consultants. SimaPro Tutoria; PRé Sustainability: LE Amersfoort, The Netherlands, 2019.

36. Ecoinvent Center. Ecoinvent Database: Version 3.7.1; Ecoinvent: Zurich, Switzerland, 2020.

37. Intergovernmental Panel on Climate Change. IPCC. Available online: http://www.ipcc.ch/ (accessed on 1 July 2020).

38. Hajibabaei, M.; Hesarkazzazi, S.; Lima, M.; Gschösser, F.; Sitzenfrei, R. Environmental Assessment of Construction and Renovation of Water Distribution Networks Considering Uncertainty Analysis. Urban Water J. 2020, 17, 723-734. [CrossRef]

39. Althaus, H.; Doka, G.; Dones, R.; Heck, T.; Hellweg, S. Ecoinvent 2 Overview and Methodology; Frischknecht, R., Niels, J., Eds.; Ecoinvent: Zurich, Switzerland, 2007. 